\title{
EFFECT OF DIFFERENT TYPES OF MILK FORMULA AGAINST STREPTOCOCCUS MUTANS BIOFILM FORMATION IN VITRO
}

\author{
MELTHARYNA MELTHARYNA, MARGARETHA SUHARSINI, HERIANDI SUTADI*
}

Department of Pediatric Dentistry, Faculty of Dentistry, Universitas Indonesia, Jakarta, Indonesia. Email: sutadi.heriandi@gmail.com

Received: 21 April 2017, Revised and Accepted: 13 July 2017

ABSTRACT

Objectives: The purpose of this study was to analyze the differences in the effect of milk-based, soy-based, and protein hydrolysate formulas against Streptococcus mutans (SM) biofilm formation.

Methods: Infant formula used is intended for children aged 1-3 years, and each respective type of infant formula is represented by three distinct brands.

Results: Our results showed a significant difference in the effect of milk-based, soy-based, and protein hydrolysate formulas against SM biofilm formation $(\mathrm{p}=0.002)$.

Conclusion: Cow's milk-based formula showed the lowest SM biofilm formation.

Keywords: Milk formula, Biofilm, Streptococcus mutans.

(C) 2017 The Authors. Published by Innovare Academic Sciences Pvt Ltd. This is an open access article under the CC BY license (http://creativecommons. org/licenses/by/4. 0/) DOI: http://dx.doi.org/10.22159/ajpcr.2017.v10s5.23088

\section{INTRODUCTION}

Early childhood caries (ECC) is a condition characterized by the presence of at least one decayed (lesions with cavities or non-cavities), missing (due to caries), or patched tooth, in the primary teeth of children aged 71 months or younger. ECC has been a problem both in the developed and the developing countries. The studies have reported that the prevalence of ECC in the US and the UK was $12 \%$ and between $11 \%$ and $53.1 \%$, respectively, whereas the prevalence of ECC in developing countries is higher, at 70\% [1]. Research from Europe, Africa, Asia, North America, and Central America shows that the prevalence of ECC is the highest in Africa and Southeast Asia [1-4]. ECC is a multifactorial problem. One of the causes of ECC is food or beverages that contain carbohydrates. For instance, milk formula can be a cause of dental caries in children. Infant formula milk on the market is divided into three types, including cow's milk, soy-based, and milk protein hydrolysate formulas. All three formulas have different nutrient content. In general, formula milk is given to babies over 6 months old, but in some specific conditions, formula milk is given babies earlier $[2,3,5]$.

The other cause for ECC is bacteria. Of the bacterial flora that can be found in the oral cavity, Streptococcus mutans (SM) is the main cause of caries. Caries begins to appear with when SM attach and form biofilms on the surface of teeth. In addition to its ability to attach and form biofilms, SM can also survive in acidic environments and can produce acids faster than other bacteria. Acid is the result of metabolic activity of SM, making it the most cariogenic bacterial species [6,7]. Changes in the amount of food and beverage intake and the type of diet may affect the development and final composition of bacterial biofilms and chemicals in the oral cavity. Diet can affect the proportion of bacterial species in the biofilms formed [8]. A study showed that the number of SM in the oral biofilms of children who consumed milk-based formula is higher than that in the biofilms of children who consumed soy-based formula [4]. Other studies have shown that the number of SM in biofilms of children who consumed milk-based formula is lower than children who consumed soy and protein hydrolysate formula [9]. This difference is possibly due to the differences in the composition of milk formula in each country. Thus, we aimed to analyze the differences in the effect of various milk formulas (including milk-based, soy-based, and protein hydrolysate formulas) on SM biofilm formation in vitro.

\section{METHODS}

This study had been approved by the Dental Research Ethical Committee, Faculty of Dentistry Universitas Indonesia (Letter Number: 23/Ethical Approval /FKGUI/VI/2016). In this study, three types of formula milk were used: Milk-based formula, soy-based formula, and protein hydrolysate formula. Formula milk for children aged 1-3 years was used, which contains 3-4 g of sucrose. Each type of milk formula was represented by three brands, selected based on the highest usage in Indonesia. The samples in this study were SM biofilm. Materials and tools used were SM serotype c, the media in order TYS20B, media TYS Broth, Osse, anaerobic jar, incubator, $0.1 \%$ crystal violet, Lugol, Safranin, alcohol 96\%, phosphate buffer saline (PBS), media BHI broth, 96\% ethanol, 96-microwell plate, and microplate reader (model 3550; BioRad Laboratories, Hercules, CA). Before use, the bacteria were stored at $-80^{\circ} \mathrm{C}$ in media trypticase soy broth. At the beginning of the study, SM was cultured on a trypticase soy agar bacitracin sucrose medium (TYS20B) and incubated in $10 \% \mathrm{CO}_{2}$, at $37^{\circ} \mathrm{C}$, for $48 \mathrm{hrs}$.

After $48 \mathrm{hrs}$, the bacteria in one of the colonies on the agar medium were gram stained, to ensure the colony comprised SM bacteria. Bacteria in TYS20B were then bred back on the TYS Broth medium for 24 hrs. Bacteria that had been cultured in the TYS Broth for 24 hrs were calculated by counting the number of colonies with a microplate reader, at a wavelength of $405 \mathrm{~nm}$. Bacteria in the TYS Broth medium were then diluted using the formula C1.V1 = C2.V2 to get as many as 108 bacteria (C2) in $1000 \mathrm{ml}$ (V2). Based on this calculation, to obtain 108/1000 ml dilution, $30 \mathrm{ml}$ TYS Broth containing bacteria were diluted with $970 \mathrm{~mL}$ of sterile distilled water. Formula milk solution was made by weighing the formula milk powder using a milligram scale. After that, the solution was incorporated into EPPIS and diluted with $1000 \mathrm{ml}$ of sterile distilled water. The solution was homogenized using a vortex mixer.

A biofilm test was conducted using a 96-well plate (microtiter plate). $10 \mathrm{ml}$ of SM bacteria were inoculated into $150 \mathrm{ml}$ of BHI broth and $40 \mathrm{ml}$ 
of milk formula that had been previously prepared in a 96-microwell plate. In addition, the microwell plate also included negative controls in the form of $200 \mathrm{ml}$ of BHI broth and a positive control in the form of $190 \mathrm{ml}$ and $10 \mathrm{ml}$ of BHI broth of bacteria. Microwell plates were inserted in an anaerobic jar containing $10 \% \mathrm{CO}_{2}$ gas, $\mathrm{N}_{2} 5 \%$, and $85 \% \mathrm{O}_{2}$ and incubated at $37^{\circ} \mathrm{C}$, for $48 \mathrm{hrs}$. After $48 \mathrm{hrs}$ of incubation, bacterial cells that did not form a biofilm on the base plate (part planktonic) were disposed. The plate was then washed with $200 \mathrm{ml}$ of PBS twice. The plate was then fixed with heat from a fire to dry the biofilm. Thereafter, $200 \mathrm{ml}$ of $0.5 \%$ crystal violet was added into each well. Biofilms were then incubation at $37^{\circ} \mathrm{C}$ for 15 minutes, with the supernatant containing residual waste solution of $0.5 \%$ crystal violet. Thereafter, the biofilms were washed with $200 \mathrm{ml}$ of PBS, and a solution of $200 \mathrm{ml}$ of $96 \%$ ethanol was added to each well on the plate. The biofilm formed was measured by its absorbance value (optical density [OD]), at a wavelength of $490 \mathrm{~nm}$, using a microplate reader. Data (OD) were analyzed using a one-way ANOVA test, with a significance of $\mathrm{p}<0.05$, to determine differences in the effect between milk-based formula, soy-based formula, and protein hydrolysate formula on SM biofilm formation. If there were significant differences among the three groups, then performed post-hoc LSD tests with significance levels of $\mathrm{p}<0.05$ were conducted to determine which groups were significantly different.

Milk formula was made following the manufacturer's instructions, to a volume of $1 \mathrm{~L}$. In this study, milk formulas were dissolved in sterile distilled water and mixed by vortexing. Milk formula used was previously unopened, to avoid contamination of milk with the outside environment. The bacteria used in this study were SM serotype c. SM is a type of bacteria that are most commonly found in plaques and are a major cause of caries. There are four SM serotypes commonly found in humans, that is, c, d, e, and f [6]. Of the four serotypes, SM serotypes c is most commonly found in humans. Seventy to eighty percent of the population of microbes in plaque is composed of SM serotype c [10]. Other study states that SM serotypes c is commonly found in children aged 3-5 years, who consume milk in a bottle [11]. Therefore, SM serotype $\mathrm{c}$ was selected in this study.

In this study, SM serotype c in stock solution was cultured beforehand, on a TYS20B medium. This medium is one of the selective media for SM. Early breeding is done on selective media to prevent contamination of other bacteria when culturing on agar. Of the existing SM selective media, TYS20B has high sensitivity [12] and was therefore used in this study. Breeding on agar media was conducted for pure colony formation using a streak plate. Single bacterial cells that are spread using the streak technique produce bacterial colonies. One colony formed come from one parent and have the same nature and character [13]. We chose this technique because the procedure is quick and simple to obtain pure colonies.

Gram staining of bacterial colonies was conducted after culturing the bacteria on agar media. Staining was performed to identify whether the bacteria present was a colony of SM. Through a microscope, the bacteria look purple and round and are arranged to resemble the form of chains. Images of SM from the literature were referenced to confirm our observations [14]. The SM colonies were then added into a solution, using the liquid TYS broth. Just like TYS20B, this liquid media was a selective medium for SM. The main SM solution was incubated for $24 \mathrm{hrs}$ following the procedure of the previous studies [15,16]. After incubation for $24 \mathrm{hrs}$, the number of bacteria in the main solution was counted by measuring the turbidity (cloudiness) of the liquid medium containing the bacterial culture. Counting the number of bacteria using this method is based on a correlation between turbidity and changes in the number of bacterial cells.

Examination of SM biofilm formation was performed using a 96well plate (microtiter plate). This technique was selected because the procedure was simple, easy to use, could be modified (either the medium used or the incubation time) to examine different aspects of the bacterial community, and could be adapted easily to studying various conditions of the formation of biofilms [17]. The incubation temperature for bacterial biofilm formation is generally $37^{\circ} \mathrm{C}$ [18]. In this study, the incubation temperature of $37^{\circ} \mathrm{C}$ was found to be optimal for the growth of SM [19]. The incubation time using this technique on a 96-well plate (micro titer plate) was 2-30 hrs [17]. Other literature mentions that the incubation time ranged from 30 minutes to $72 \mathrm{hrs} \mathrm{[20].} \mathrm{In} \mathrm{general,} \mathrm{timing} \mathrm{is} \mathrm{based} \mathrm{on} \mathrm{the} \mathrm{stage} \mathrm{of} \mathrm{biofilm} \mathrm{formed}$ and is decided by observation. In this study, the biofilm formed was examined when it reached the stage of maturation. An in vitro study of biofilm formation either in a single species or multispecies shows that biofilm maturation occurs at 24-72 hrs [21]. In this study, the incubation time was $48 \mathrm{hrs}$. This is also the time when biofilm in the oral cavity undergoes maturation [22].

\section{RESULTS}

The results were read with a microplate reader, at a wavelength of $490 \mathrm{~nm}$. Higher values of OD indicated SM biofilm formation. Fig. 1 shows that the highest mean OD value was obtained using the soybased formula, whereas the mean OD value of milk-based formula was the lowest. All values of formula milk OD were greater than the positive control.

Data were tested using a one-way ANOVA. The normality test used was the Shapiro-Wilk test for a sample of $27(<50)$. All $p$ values for each group in the tests of normality were $>0.05$, indicating the normal distribution of data. Furthermore, the homogeneity of variance test data was performed on each group of milk formula used. The $p$-value in the third group of milk formula was $>0.05$ (milk-based formula $\mathrm{p}=0.362$; soy-based formula $\mathrm{p}=0.613$, and protein hydrolysate formula $\mathrm{p}=0.324$ ). This shows that the variance of data in each group was homogeneous. The test for variance between groups shows that data were homogeneous in this study ( $p=0.053)$. Thus, both requirements for using a one-way ANOVA were fulfilled. The results of the one-way ANOVA are given in Table 1

The one-way ANOVA test showed significant differences $(p<0.05)$ in SM biofilm formation among the three groups of milk formulas. Specifically, there were significant differences in SM biofilm formation in the third group of milk formula; milk-based formula and protein hydrolysate formula group had significantly lower values than soy-based group, on performing the post-hoc LSD test (Table 2).

Table 2 shows that there were significant differences in SM biofilm formation between the cow's milk and soy-based formula group $(p<0.05)$, as well as between the soy-based and protein hydrolysate formula groups $(p<0.05)$, whereas no significant difference $(p>0.05)$ of SM biofilm formation was observed between cow's milk and protein hydrolysate formula groups.

\section{DISCUSSION}

This study used three types of milk formula such as milk-based formula, soy-based formula, and protein hydrolysate formula to analyze their effect against SM biofilm formation. The three types of milk formula were selected from formula milk products circulating freely in the Indonesia's market and easily accessible by the public. Each milk formula has a different usage indication. Milk formula used in this study is intended for children aged between 1 and 3 years. This age range is selected because of the high prevalence of ECC in children between 1 and 3 years of age [23]. In addition, based on the literature, the infectivity and the initial acquisition of SM occur at the age range between 9 and 44 months, which coincides with the period of primary tooth eruption [24]. In this study, tests performed on the biofilm due to the bacteria present showed that bacteria can survive in adverse conditions, where even planktonic bacteria cannot survive. Moreover, the bacteria from biofilms are more resistant to antimicrobial agents and the immune system. Both these factors lead to an increase in bacterial pathogenicity [25]. The biofilms examined in this study are those that have undergone maturation. This 
Table 1: Result analysis of one-way ANOVA SM biofilm formation

\begin{tabular}{lll}
\hline Type of milk formulas & OD value mean \pm SD & p-value \\
\hline Milk-based formula & $1.902 \pm 0.676$ & $0.002^{*}$ \\
Soy-based formula & $2.777 \pm 0.169$ & \\
Protein hydrolysate formula & $2.263 \pm 0.344$ & \\
\hline
\end{tabular}

*Significant $\mathrm{p}<0.05$

\section{Table 2: LSD post-hoc analysis}

\begin{tabular}{ll}
\hline Groups & p-value \\
\hline Milk-based formula versus soy-based formula & $0.001^{*}$ \\
Milk-based formula versus protein hydrolysate formula & 0.115 \\
Soy-based formula versus protein hydrolysate formula & $0.029 *$ \\
\hline *
\end{tabular}

*Significant $\mathrm{p}<0.05$

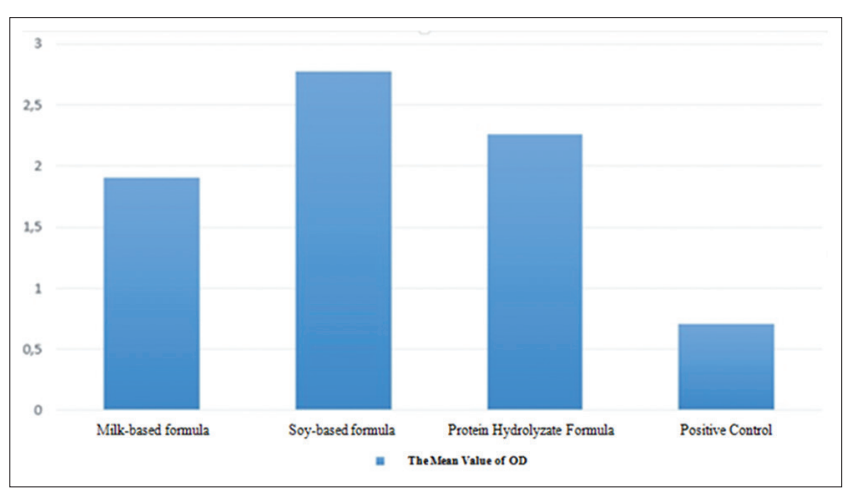

Fig.1: Diagram rod SM Biofilm formation on various milk formulas

stage is characterized by an increase in the number of bacteria and exopolysaccharide matrix. Mature biofilms comprise a higher number of SM [19]. The increase in the number of SM has a positive correlation with the prevalence and incidence of caries [6]. An increasing number of exopolysaccharide matrices is also accompanied by an increase in the number of extracellular polysaccharides. Extracellular polysaccharide biofilms are a virulence factor for facilitating the attachment of bacteria to the tooth surface, contributing to the structural integrity of the biofilm, and increasing the porosity of the biofilm formed, thereby allowing carbohydrates to diffuse into the deepest part of the biofilm resulting in a low $\mathrm{pH}[26]$.

The volume of milk formula on the microwell plate is $20 \%$ of the total volume of the solution. These percentages have been able to describe the effect of milk formula against SM biofilm formation. The volume of SM in the microwell plate is $10 \mu \mathrm{l}$. We selected this volume as per SM volumes in the previous research $[15,16]$. The results of the one-way ANOVA conducted showed significant differences in the SM biofilm formation of cow, soy, and protein hydrolysate formulas. The cow's milk-based formula had the lowest average OD value, indicating that the formation of biofilm was less in this formula compared to both the other formulas, even though the cow's milk-based formula had two kinds of carbohydrates in it, sucrose (4 g) and lactose (9-10 g), which could potentially increase biofilm formation of SM. The low value of OD may be because the cow's milk-based formula contains casein, which has antibacterial properties. The literature mentions that casein may inhibit the attachment of SM to the surface of the substrate, by reducing the activity of the enzyme glucosyltransferase $[21,27]$.

The mean OD value is the highest in the soy-based formula used, indicating that this formula results in the most SM biofilm formation compared to the other two types of milk formula. Increased formation of biofilm on soy-based formula is due to the high sucrose content of the soy-based formula. Sucrose is the most cariogenic carbohydrate because it can be fermented by SM and is a substrate for the formation of biofilm matrices, extracellular polysaccharides, and polysaccharide intracellular biofilms [26]. Biofilms formed due to the presence of sucrose have a higher number of SM, thus increasing the potential for caries formation. Sucrose also supports bacterial colonization, and thus, biofilm formation increases further [22]. Compared to the cow's milk-based formula, sucrose in the soy-based formula used is less than 3 grams. The OD value in the soy-based formula should thus be smaller than that of the milk-based formula, which contains both sucrose and lactose. However, in this study, the value of OD on soy-based formula is the highest. The mean OD value of the protein hydrolysate formula is between the OD values of the cow's milk based and the soy-based formula. Despite having the same carbohydrate content, the average OD of the protein hydrolysate formula is lower compared to the soy-based formula. This may be because the protein hydrolysate milk formula also contains casein. Despite having been hydrolyzed, the casein in the protein hydrolysate milk formula likely still has antibacterial properties, although more evidence is needed to confirm this result. The results of this study differ from the previous studies; however, this may be because the milk formula circulating in each country have different properties [4]. This study used milk formulas circulating in Indonesia so that research results illustrate the effect of various types of milk formula specific to that region.

This study only targeted the differences in SM biofilm formation in three types of milk formula. To determine which milk formula has the potential for more caries, additional research is needed, especially regarding the formation of extracellular polysaccharides (which cause virulence of biofilms) and the formation of intracellular polysaccharides (which causes a decrease in $\mathrm{pH}$, resulting in the demineralization of teeth). The OD value of the third milk formula is higher than that of the positive control group. This is because of the high carbohydrate content of milk during bottle-feeding. Carbohydrates, lactose, and sucrose can increase the biofilm formation of SM [28]. Even though SM biofilm formation was the lowest in the cow's milk based formula, it does not mean that this formula is the best. SM biofilm formation in milk-based formulas was higher than the positive control. The literature mentions that an increase in biofilm formation is directly proportional to the amount of the increase in the number of SM, and SM is directly proportional to the likelihood of occurrence of caries [6]. Based on these results, dentists are expected to further motivate parents to start the early cleaning of the oral cavity, especially in children who consume soy and protein hydrolysate formulas.

\section{CONCLUSION}

Cow's milk-based formula showed the lowest SM biofilm formation, and there were differences in the effect of cow's milk-based formula, soybased formula, and protein hydrolysate formula on the formation of the SM biofilm. There is further need for research on aspects related to this study, such as the formation of biofilm extracellular polysaccharides, intracellular polysaccharides, or the $\mathrm{pH}$ of biofilms. In addition, further research needs to be done by comparing the effects of casein contained in milk-based formulas and hydrolyzed casein in protein hydrolysate formulas in SM biofilm formation.

\section{REFERENCES}

1. Kumar VD. Early childhood caries-an insight. J Int Oral Health 2010;2(1):1-9.

2. Dean JA, Avery DR, McDonald RE. Dentistry for the Child and Adolescent. Missouri: Elsevier Health Sciences; 2010.

3. Chaudhary SD, Chaudhary M, Singh A, Kunte S. An assessment of the cariogenicity of commonly used infant milk formulae using microbiological and biochemical methods. Int J Dent 2011;2011:1-9.

4. de Mazer Papa AM, Tabchoury CP, Del Bel Cury AA, Tenuta LM, Arthur RA, Cury JA. Effect of milk and soy-based infant formulas on in situ demineralization of human primary enamel. Pediatr Dent 2010;32(1):35-40

5. PAHO, WHO. Guiding Principles for Complementary Feeding of the Breastfed Child. Geneva: Pan American Health Organization, World Health Organization; 2002. 
6. Samaranayake LP, Jones BM. Essential Microbiology for Dentistry. $2^{\text {nd }}$ ed. London: Churchill Livingstone; 2001.

7. McGhee JR, Michalek SM, Cassell GH. Dental Microbiology. $4^{\text {th }}$ ed. Philadelphia, PA: Harper \& Row; 1982.

8. Bowden GH, Li YH. Nutritional influences on biofilm development. Adv Dent Res 1997;11(1):81-99.

9. Erickson PR, McClintock KL, Green N, LaFleur J. Estimation of the caries-related risk associated with infant formulas. Pediatr Dent 1998;20(7):395-403

10. Palmer EA, Nielsen T, Peirano P, Nguyen AT, Vo A, Nguyen A, et al. Children with severe early childhood caries: Pilot study examining Mutans streptococci genotypic strains after full-mouth caries restorative therapy. Pediatr Dent 2012;34(2):1-10.

11. Fauziah E. Prediksi resiko sindroma karies botol berdasarkan polimorfisme gen glucosyltransferase Streptococcus mutans dan level mucin MG2 saliva. Jakarta: Universitas Indonesia; 2013.

12. Wan AK, Seow WK, Walsh LJ, Bird PS. Comparison of five selective media for the growth and enumeration of Streptococcus mutans. Aust Dent J 2002;47(1):21-6.

13. Mehrotra RS. Principles of Microbiology. New Delhi: McGraw-Hill Education Pvt Limited; 2009.

14. Marsh PD, Martin MV. Oral Microbiology. $4^{\text {th }}$ ed. Oxford, UK: Elsevier Health Sciences; 1999.

15. Allison LM, Walker LA, Sanders BJ, Yang Z, Eckert G, Gregory RL. Effect of human milk and its components on Streptococcus mutans biofilm formation. J Clin Pediatr Dent 2015;39(3):255-61.

16. Nassar HM, Li M, Gregory RL. Effect of honey on Streptococcus mutans growth and biofilm formation. Appl Environ Microbiol 2012;78(2):536-40.
17. Merritt JH, Kadouri DE, O'Toole GA. Growing and analyzing static biofilms. Curr Protoc Microbiol 2005; Chapter 1:Unit 1B.1.

18. Coffey BM, Anderson GG. Biofilm formation in the 96-well microtiter plate. Methods Mol Biol 2014;1149:631-41.

19. Gronroos L. Quantitative and Qualitative Characterization of Mutans streptococci in Saliva and in the Dentition. Helsinki: University of Helsinki; 2000.

20. Seneviratne CJ, Zhang CF, Samaranayake LP. Dental plaque biofilm in oral health and disease. Chin J Dent Res 2011;14(2):87-94

21. Johansson I. Milk and dairy products: Possible effects on dental health. Food Nutr Res 2002;46(3):119-22.

22. Mount GJ, Hume WR. Preservation and Restoration of Tooth Structure. $2^{\text {nd }}$ ed. Queensland: Knowledge Books and Software; 2005.

23. Colak H, Dülgergil CT, Dalli M, Hamidi MM. Early childhood caries update: A review of causes, diagnoses, and treatments. J Nat Sci Biol Med 2013;4(1):29-38.

24. Law V, Seow WK, Townsend G. Factors influencing oral colonization of mutans streptococci in young children. Aust Dent J 2007;52(2):93-100.

25. Chandki R, Banthia P, Banthia R. Biofilms: A microbial home. J Indian Soc Periodontol 2011;15(2):111-4

26. Kim YS, Lee ES, Kwon HK, Kim BI. Monitoring the maturation process of a dental microcosm biofilm using the Quantitative Lightinduced Fluorescence-Digital (QLF-D). J Dent 2014;42(6):691-6.

27. Vacca-Smith AM, Van Wuyckhuyse BC, Tabak LA, Bowen WH. The effect of milk and casein proteins on the adherence of Streptococcus mutans to saliva-coated hydroxyapatite. Arch Oral Biol 1994;39(12):1063-9.

28. Assaf D, Steinberg D, Shemesh M. Lactose triggers biofilm formation by Streptococcus mutans. Int Dairy J 2015;42:51-7. 